\title{
Anatomical Study of Caudal Vertebrae of Estuary Crocodile (Crocodylus porosus), Chameleon (Bronchocela jubata) and Klarap (Draco volans)
}

\author{
Aidha Rosel, Safitri Anggita Tunjung Sari, Umi Uswatun Hasanah* \\ Biology Department, Faculty of Science and Technology, UIN Sunan Kalijaga \\ J1. Marsda Adisucipto No. 1 Yogyakarta 55281, Indonesia. Tel. + 62-274-540971, Fax. + 62-274-519739 \\ Email: umiuswatun41@gmail.com
}

\begin{abstract}
Reptile tails have a unique function as self defense, autotomy, and maintaining balance while in nature. There are several species that do not have an autotomy function, these species include Estuary Crocodile (Crocodylus porosus), Java Chameleon (Bronchocela jubata), and Klarap (Draco volans). The species is a reptile class that uses its tail with different functions. Differences in function in the tail can be caused by differences in anatomical structure, morphology, and behavioral adaptations that are owned by each species. With the differences in each species, this study aims to get a comparative picture of the caudal vertebrae (coccyx) anatomy of species of estuary crocodile (Crocodylus porosus), java chameleon (Bronchocela jubata), and klarap (Draco volans) so that anatomical comparison can be seen in each species that affects the difference in tail function. The method used in this study is morphological observation with boiled method, X-Ray method, and Alizarin Red's and Alcian Blue staining methods. Research that has been conducted shows that the anatomical structure of caudal vertebrae (coccyx) in estuary crocodile species has a larger bone structure than the bone structure of java chameleon and klarap. The anatomical structure of caudal vertebrae (coccyx) in klarap has a smaller bone structure than estuary crocodile and java chameleon. The anatomical structure of caudal vertebrae (coccyx) in java chameleon species has a longer bone structure than its body length. Caudal vertebrae of these three species do not have tail fracture fields.
\end{abstract}

Keywords: Anatomy, Estuary crocodiles (Crocodylus porosus), Java chameleon (Bronchocela jubata), Klarap (Draco volans), Caudal vertebrae

\section{INTRODUCTION}

Every animal has a certain way to protect itself from enemy threats and its environment. In Reptile classes, especially certain Lacertilia members have the ability to break their tails when threatened. In addition to breaking the tail, reptiles protect themselves by changing skin color (Lestari, 2016; Simanulang, 2013).

The tail function that is owned by the Reptile class besides having the ability to self-defense, the tail also functions for autotomy, and maintains balance when in nature. There are several reptile animals that have autotomy and not autotomy. Autotomy is the ability of a living creature to cut its body parts automatically. One of the reptiles that experienced autotomy was a lizard snake (Anguis fragilis). But there are some reptiles that do not have an autotomy function so that the tail of a reptile has a different function in its survival. Reptiles without autotomy include estuary crocodile (Crocodylus porosus), java chameleon (Bronchocela jubata) and klarap (Draco volans) (Lestari, 2016).

Estuary crocodile (Crocodylus porosus) uses its tail to help swim in the water. Java chameleon (Bronchocela jubata) is a member species of the Reptile that has a movement pattern by wrapping its tail on a tree branch and using its tail to defend itself from the enemy, as well as helping in the process of foraging. Klarap (Draco volans) uses its tail to balance its body while flying, so its tail is used as a steering wheel while flying (Simanulang, 2013; Syarif, 2013).

Tail functions that are different from the tail of the Reptile can be studied about the comparative anatomy of estuary crocodile, java chameleon, and klarap there also are different functions of each tail owned by the three animals. So the research can be done with the aim to get an overview of the comparative anatomical structure of the caudal vertebrae (coccyx) in three species.

From this description, the problem can be drawn about how is the comparison of the anatomical structure of the caudal vertebrae (coccyx) species of estuary crocodile (Crocodylus porosus), java chameleon (Bronchocela jubata), and Klarap (Draco volans).

\section{MATERIALS AND METHODS}

\section{Tools}

Tools that used in this study include cages equipped with water and food, X-Ray (Shimadzu), surgical instruments, stereo microscopes (Nikon SMZ1500), glass beaker, flakon bottles, tissue, cotton, cup petri, scissors, drip pipettes, gauze, tubes and tube plugs. 


\section{Materials}

Material that used in the study was an object animal that included estuary crocodile (Crocodylus pososus) with 1.16 meter long, adult java chameleon (Bronchocela jubata) with length $62 \mathrm{~cm}$, and adult klarap (Draco volans) with length $14.7 \mathrm{~cm}$. Each specimen has 3 animal samples as replications. The materials used are alcohol, 4\% formalin, Alizarin Red $S$, Alcian Blue, $\mathrm{KOH}$, acetone, glycerin, chloroform, glacial acetic acid, razor blade, and paraffin.

\section{Methods}

Data collection for preparations was caudal vertebrae carried out several methods are boiled method, X-Ray method, and Alizarin Red's staining method and Alcian Blue (Inouye, 1976).

\section{RESULTS AND DISCUSSION}

Based on the research, a comparison of morphological structures in estuary crocodile (Crocodylus porosus), java chameleon (Bronchocela jubata), klarap (Draco volans). The comparison is as follows:

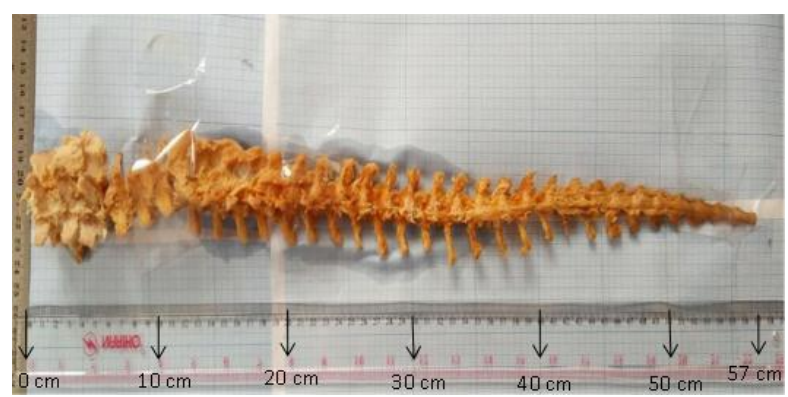

Figure 1. Morphological structure of the tail of estuary crocodile (Crocodylus porosus)

The crocodile studied has a tail length of $56 \mathrm{~cm}$ from the base of the tail to the tip of the tail (Figure 1). The morphology of estuary crocodile has a brown complexion with large and tight teeth and is black with black and brown stripes (Kurniati et al., 1999). Estuary crocodile have 30 caudal vertebrae from the base to the tip of the tail. The color of the estuary crocodile tail bone is yellowish brown.

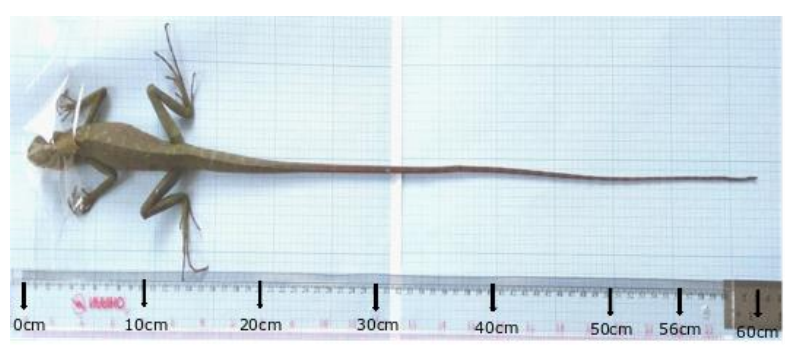

Figure 2. Chameleon body morphology structure (Bronchocela jubata) from dorsal.
The chameleon studied has a tail length of $62 \mathrm{~cm}$ from the base of the tail to the tip with a light blue striped green pattern on the body (Figure 1). Chameleon tail has a length 3.7 times the body length (Table 1). The base of the tail until the tip looks morphologically the slender the tail shape. The slim function of the chameleon's tail to help the chameleon wrap its tail (Kurniati, 2004).

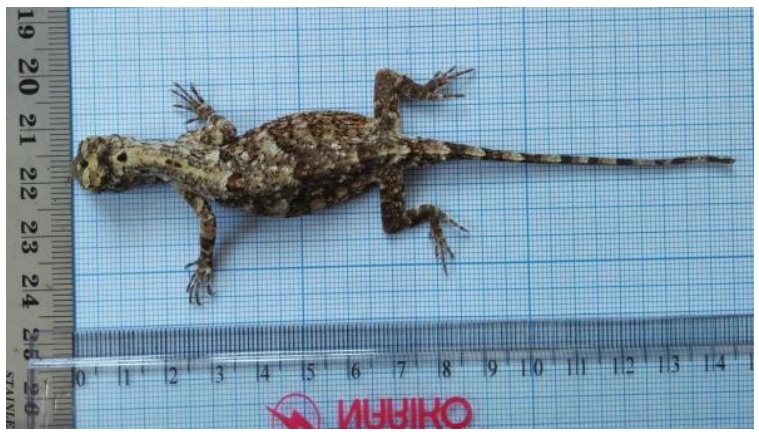

Figure 3. Morphological structure of Klarap (Draco volans) body from dorsal.

Klarap used in this study has a body length of 14.7 $\mathrm{cm}$ (Figure 3). Klarap's wings have a dark brown and the body is black and hues orange. The body characteristic of klarap is a round black pattern from the top of his head. In the body part of klarap has 3 round black patterns visible from dorsal (Figure 8). This kind of color pattern is a good disguise on tree branches. Klarap (Draco volans) has a pair of wings that are modifications rib and integument called patagium.

The ratio of body length and tail of the estuary crocodile has the same ratio of 1: 1 . Comparison of java chameleon body length and tail has a different ratio of 1: 3,7. Whereas in Klarap, the ratio of body length and tail has the same ratio of 1: 1 (Table 1).

Table 1. Morphometry of specimens.

\begin{tabular}{llll}
\hline Species Parameter & $\begin{array}{l}\text { Bronchocela } \\
\text { jubata }\end{array}$ & $\begin{array}{l}\text { Draco } \\
\text { volans }\end{array}$ & $\begin{array}{l}\text { Crocodylus } \\
\text { porosus }\end{array}$ \\
\hline $\begin{array}{l}\text { Standard body length } \\
(\mathrm{cm})\end{array}$ & 13 & 7,3 & 60 \\
Tail length (cm) & 49 & 7,4 & 56 \\
$\begin{array}{l}\text { Total body length } \\
(\mathrm{cm})\end{array}$ & 62 & 14,7 & 116 \\
\hline
\end{tabular}

Based on morphology, the tail length of the three animal species can associated with its function. Estuary crocodile (Crocodylus porosus) has a long, large and strong tail. This helps the estuary crocodile to swim in the water. Java chameleon uses its tail as self-protection and balance to hold on to branches and ratings by wrapping the tip of its tail on a tree. While the tail of klarap (Draco volans) has the same tail length as his body. Klarap's tail function for balance when moving from one branch to the other (Kurniati, 2003). 


\section{Observation of Preparation Caudal Vertebrae with Boiled Method}

The boiled method is done to observe the structure of the tail bone clearly. Heating preparations takes 15 minutes maximum, if you take too long to warm up the preparation will be easily brittle.

Observation of tail estuary crocodile, java chameleon and klarap from anterior consists of neural spine, post-zygapophysis, pre-zygapophysis, spinal cord, centrum, chevron bone, hemalis process, and lateral process (Figure 4).

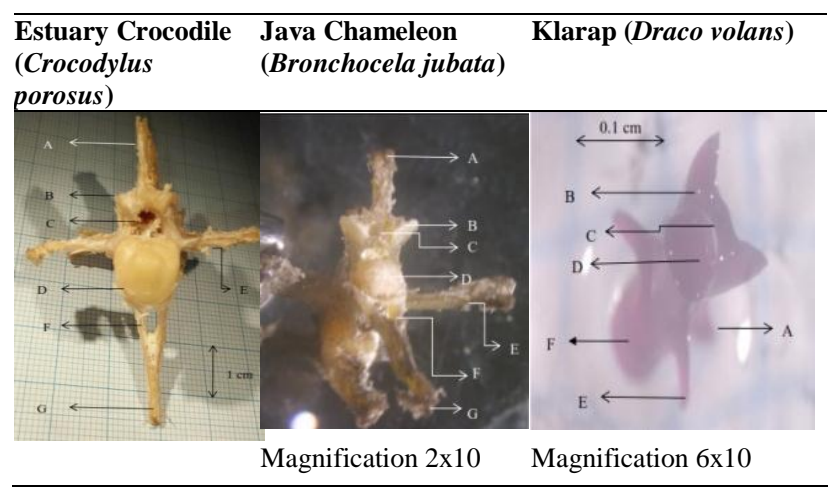

Figure 4. Structure of caudal vertebrae the third specimens of the anterior using a stereo microscope (excluding the vertebrae of crocodiles), Description: A: Spina neural, B: Pre-zygapophysis, C: Spinal cord, D: Centrum, E: Processus lateralis, F: Chevron bone, G: Process of hemalis.

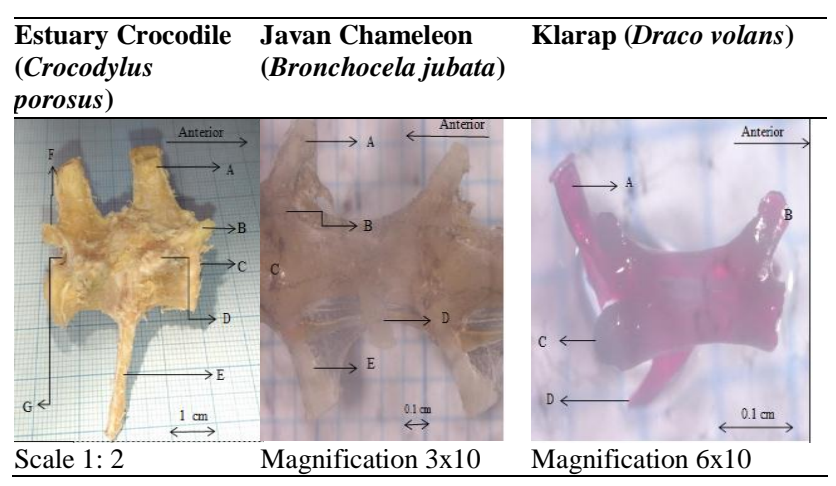

Figure 5. The structure of caudal vertebrae the third specimens from the lateral direction using a stereo microscope (except caudal vertebrae crocodile), Description: A: Spina neural, B: Pre-zygapophysis, C: Centrum, D: Processus lateralis, E: Processus hemalis, F: Postzygapophysis, M: Spinal cord.

Observation of tail estuary crocodile, java chameleon and klarap from the lateral direction morphologically shows the tail parts are composed of neural spine, lateral process, post-zygapophysis, pre-zygapophysis and hemalis process. Hemalis process of estuary crocodile has the longest $(2.3 \mathrm{~cm})$. Hemalis process of java chameleon has a length of $0.3 \mathrm{~cm}$. The hemalis process of klarap has a length of $0.1 \mathrm{~cm}$ (Figure 5). Neural spine of estuary crocodile is $1.5 \mathrm{~cm}$ long. Java chameleon has a neural spine $0.3 \mathrm{~cm}$ long and klarap has a neural spine with a length of $0.1 \mathrm{~cm}$. The estuary crocodile have the hemalis process longer than the neural spine. While java chameleon and klarap have the hemalis process and neural spine with the same length (Figure 5).

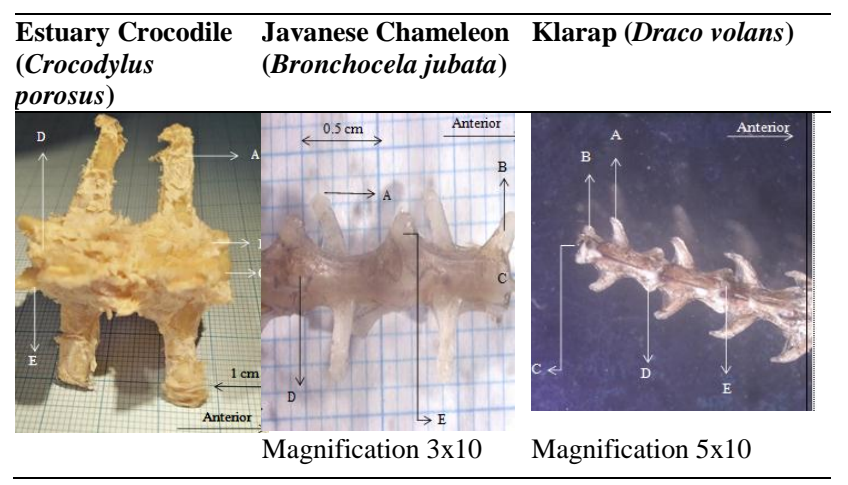

Figure 6. Structure of caudal vertebrae of three specimens from the ventral direction using a stereo microscope (except caudal vertebrae of crocodile), Description: A: Lateral process, B: Chevron bone, C: Hemalis process.

Three preparations of caudal vertebrae have differences structure. The difference is the length of the caudal vertebrae, size of centrum, position of the lateral process. One of the most prominent positions of this difference is the laying of the lateral process bone on all three preparations. The lateral process part of the estuary crocodile and java chameleon has a parallel bone direction. While the lateral process of the klarap toward the posterior.

Estuary crocodile (Crocodylus porosus) using its tail as a motion aid to swimming and walking. It is shown that estuary crocodile have a large and strong tail bone structure (Figure 5). The centrum of estuary crocodile have a round and large shape compared to chameleon and klarap (Figure 4). The centrum has the function of holding the main load between vertebrae. The hemalis process of estuary crocodile has the same length as the lateral process (Figure 6). These parts can be addressed to help the crocodile motion in swimming (Kurniati, 2003).

Java chameleon (Bronchocela jubata) uses its tail as a movement pattern by wrapping its tail on a tree trunk or twig. It can be shown clearly that the structure of the chameleon tail is very long with a size of $30 \mathrm{~cm}$ (Figure 7). Caudal vertebrae in chameleon are small and oval in size with a length of $0.3-0.5 \mathrm{~cm}$. The bone structure of the chameleon can be linked to make it easier to wrap its tail around a tree branch (Pratt, 1946).

Klarap (Draco volans) has a very small bone structure (Figures 4, 5, 6, and 7.). The small part of the bone structure shows klarap (Draco volans) using its tail as a balance when moving from one branch to another. Flying ability of Draco volans using wings while the tail is used as a steering wheel to moving in the air and cannot experience autotomy (Simanulang, 2013; Syarif, 2013). 


\section{Observation of Caudal Vertebrae Preparations with $X$-ray Method}

Observation was used $X$-ray to determine the axial skeleton structure of the caudal vertebrae and see the composition of the tail bone of the estuary crocodile (Crocodylus porosus), java chameleon (Bronchocela jubata) and klarap (Draco volans).

The caudal vertebrae of the three animals has a complex vertebral structure. Bone structure of complex caudal vertebrae is the lateral process, neural spine, hemalis process, pre-zygapohysis, post-zygapophysis, medulla spinal and centrum (Weichert, 1970; Hildebrand, 1976).

Estuary crocodile bone structure is bigger than java chameleon and klarap when observed using $x$-ray (Figure 7). The hemalis process and neural spine is along the tail starts from the base to the tip of the tail. So that it can help the process of estuary crocodile movement to the right and left (Kurniati, 2003).

Java chameleon (Bronchocela jubata) (Figure 7) has a smaller tail bone structure compared to estuary crocodiles and has a more extended tail structure from its body. The structure of the caudal vertebrae 11 to the tip of the tail has a longer tail structure and does not have a segment lateral process. This is related to the function of the tail to wrap when in the tree (Kurniati, 2003).

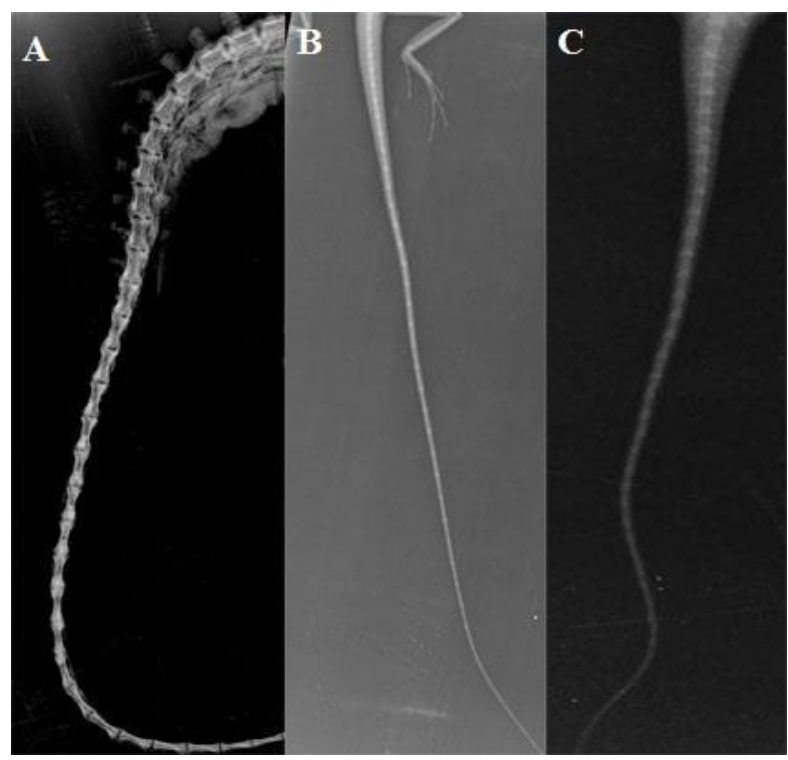

Figure 7. Axial skeleton tail with $X$-ray from dorsal direction, A Estuary crocodile, B. Java chameleon, C. Klarap, V1: $1^{\text {st }}$ Vertebrae, V5: $5^{\text {th }}$ Vertebrae, V10: $10^{\text {th }}$ Vertebrae, V11: The $11^{\text {th }}$ Vertebrae.

Klarap (Draco volans) (Figure 7) has a smaller tail bone structure than crocodile and chameleon. Klarap has a complex bone structure from caudal vertebrae 15. The structure of the $6^{\text {th }}$ caudal vertebrae until the end tail has no lateral process. This is the same as in estuary crocodile and java chameleon. Thus, the structure of caudal vertebrae of the three species can be related to tail function (Lestari, 2016).
Observation of Preparation Caudal Vertebrae Using Alizarin Red's and Alcian Blue Method (Inouye, 1976)

The observation of caudal vertebrae preparation was using Alizarin red's and Alcian blue staining to distinguish hard bone tissue and cartilage. This staining method of bone will be red, while cartilage will be blue. This coloring is only used to color small bones (Inouye, 1976; Puchler 1986). So this coloring is only used for observing caudal vertebrae of java chameleon (Bronchocela jubata) and klarap (Draco volans).

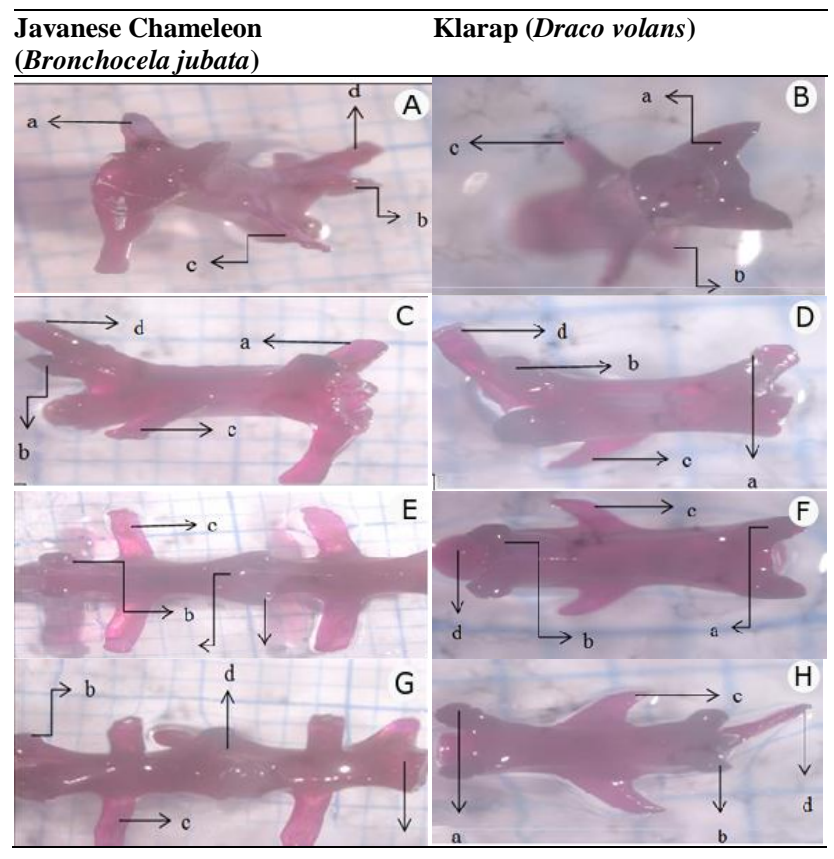

Figure 8. Skeleton image of Java chameleon tail and Klarap with Alizarin red's and Alcian blue staining. A. Java chameleon skeleton from anterior, B. Klarap skeleton from anterior, C. Java chameleon skeleton from lateral, D. Klarap skeleton from lateral, E. Java Chameleon skeleton from dorsal, F. Klarap skeleton from dorsal direction, G. Java chameleon skeleton from the ventral, H. Skeleton from the ventral with the information: a. Pre-zygapophysis b. Post-zygapophysis, c. Lateral process, d. neural spine.

Observation on the java chameleon and klarap skeleton from the dorsal (Figure 8) has parts in the form of neutralist pre-zygapophysis, neural spine, postzygapophysis, and lateral process. Observation of the chameleon tail has a long lateral process structure. Whereas in the case of the part of the lateral process, it is pushed back and not long. The hemalis process of observing the skeleton of the javanese chameleon and klarap from the ventral (Figure 8) are equally invisible. Observations on intact preparations of the java chameleon skeleton and klarap show the structure of the tail is tubular and red. This is because the calcification process has occurred to the bone.

The observation of the java chameleon and klarap skeleton from the anterior (Figure 8.) shows that the calcified bone structure will be red. Observations of the caudal vertebrae on the java chameleon (Bronchocela jubata) using a stereo microscope (Figure 8) showed several parts, namely pre-zygapophysis, neural spine, 
spinal cord, centrum, chevron bone, haemalis process, post-zygapophysis and lateral process. Whereas in klarap (Figure 8) it is seen from the anterior showing the part of pre-zygapophysis, centrum and lateral roses.

At the staining of the pre-zygapophysis and postzygapophysis, the result is dark blue (Figure 8). The dark blue shows the presence of cartilage. This part of pre-zygapophysis and post-zygapophysis functions as a site for bone attachment (Eames, 1983). Therefore, all java chameleon and klarap bone segments except the pre-zygapophysis and post-zygapophysis parts are hard bones. According to (Lutfi, et al., 2003), if the color of the bone is getting red, the calcium ion will increase and show that the calcification process is more perfect.

\section{CONCLUSIONS}

Based on the results of observations and data analysis and the discussions that have been carried out, the following conclusions are obtained:

1. The tail of the java chameleon has a relatively longer structure which is 3.7 times the length of its body compared to estuary crocodile and klarap which has a ratio of body length and tail length of 1: 1 .

2. The anatomical structure caudal vertebrae (tail bone) in estuary crocodile species has a relatively larger bone structure $(2 \mathrm{~cm})$ than the bone structure of java chameleon $(0.3 \mathrm{~cm})$ and klarap $(0.1 \mathrm{~cm})$.

3. Estuary crocodile have a lateral process in the dorsal centrum. While java chameleon and klarap have a lateral process that is parallel to the centrum. The structure of caudal vertebrae the lateral process of estuary crocodile and java chameleon has a direct direction towards the side of the bone. Whereas the caudal vertebrae part of the lateral process of the tail are inclined towards the back (posterior).

\section{ACKNOWLEDGMENTS}

The author would like to thank to the management of apprenticeship program of faculty of science and technology for guidance during the research, to the management of biology, medicine and natural product chemistry \& kaunia journal for assistance in paper writing.

\section{REFERENCES}

Eames, E.D dan Termine J.D. 1983. Calcium In Mineralized Tissues In Calcium Biology. New York : John willey dan sons. Hal 5661.

Hildebrand, M. 1976. Analysis of Vetebrae Structure. 2nd Ed. New York : John Wiley dan Sons. Hal 495-499.

Inouye, M. 1976. Deferential Staining of Kartilago and Bone in Fetal Mouse Skeleton by Alician Blue and Alizarin Red S. Journal Congetial Anomalies 161.Hal 171-173.

Kurniati, H. 2003. Mengenal Jenis-Jenis Londok di Taman Nasiona Gunung Halimun. Jurnal Fauna Indonesia, Vol. 5, No.2: 17-22.

Lestari, S. 2016. Keanekaragaman Reptil di Repong Damar Pekon Pahmungan Pesisir Barat (Studi Kasus Plot Permanen Universitas Lampung). Jurnal MIPA Lampung. Vol. 4, No. 1: 51-60.

Luthfi, M. J, Soesilo, N.P, dan Sagi, M. 2003. Kalsifikasi Skeleton Aksial pada regenerat Ekor Kadal (Mabouya multifasciata Kuhl). Jurnal Berkala Ilmiah Biologi, Vol. 3, No. 1:1-8

Pratt, C. W. M. 1946. The Plane of Facture of The Caudal Vertebrae of Certain Lacertilians. Journal of Anatomy 80: 184-188

Puchler, H; Meloan S.N; Terry, M.S. 1969. On The History and Mechanism of Alizarin and Alizarin Reds Stains For Calcium. The Journal of Histochemistry and Citochemistry, Vol.17, No. 2: $110-124$.

Simanullang, S. 2013. Struktur Makro dan Mikro Anatomi Vertebra Caudalis Bunglon (Bronchocela jubata) Dumeri

Syarif, R. 2013. Gambaran Anatomi dan Histologi Ekor Klarap (Draco Volans L, 1958). Tesis. Universitas Islam Negeri Sunan Kalijaga Yogyakarta. Hal 5-8.

Weichert, C.K. 1970. Anatomy of The Chordates Fourth Edition. Tokyo: Mc Graw hill book company. Hal 34-40. 
THIIS PA GE INTENTIONALLY LEFT BLANK 